J. Clin. Chem. Clin. Biochem.

Vol. 20, 1982, pp. 29-38

\title{
Zum Einfluß von Hämolyse, Harnstoff und Bilirubin auf die Präzision radioimmunologischer Digoxin- und Insulin-Bestimmungen
}

\author{
Von A. Dwenger und I. Trautschold \\ unter Mitarbeit von Birgitt Nentwig, Gabriele Röllig und $P$. Tost
}

Aus der Abteilung für Klinische Biochemie des Zentrums Biochemie der Medizinischen Hochschule Hannover

(Eingegangen am 27. März/20. August 1981)

Zusammenfassung: Der Einfluß von Hämolyse, Urämie und Hyperbilirubinämie auf die radioimmunologischen Digoxin- und Insulin-Bestimmungen wird für jeweils fünf Trenntechniken (Dextran/Charcoal; Coated tube; Polyethylenglykol 4000; Natriumsulfit; Doppelantikörper-Methode) untersucht. Wiederfinderaten sowie intra- und interassayPräzision werden ermittelt. Hierbei zeigt sich, daß auch in Serumproben mit hohen Hämolysegraden $(\mathrm{Hb} \leqslant 50 \mathrm{~g} / \mathrm{l})$ Digoxin nahezu störungsfrei bei Anwendung jeder der fünf Trenntechniken gemessen werden kann. Bei der InsulinBestimmung kommt es bei allen Trenntechniken im Bereich der sichtbaren Hämolyse ( $\mathrm{Hb} \geqslant 200 \mathrm{mg} / \mathrm{l})$ zu Störungen bzw. zu einem vollständigen Versagen des Tests. Dieser Einfluß kann unter deutlicher Verbesserung der Präzision durch N-Ethylmaleinimid weitgehend aufgehoben werden. Die intraassay-Präzision liegt mit Ausnahme der Coated tube-Trenntechnik unter $10 \%$ VK, die interassay-Präzision zwischen 10 und $20 \%$. Ein störender Einfluß erhöhter Harnstoff-Konzentrationen wird bei der Digoxin-Bestimmung nur im Coated tube-Test beobachtet, bei der InsulinBestimmung dagegen im Coated tube- und im Doppelantikörper-Trennverfahren. Die intraassay-Präzision liegt ebenfalls bei Variationskoeffizienten bis $10 \%$, die interassay-Präzision zwischen 10 und $20 \%$ VK. Bilirubin beeinflußt die Digoxin-Bestimmung mit Natriumsulfit-Trenntechnik und die Insulin-Bestimmung mit Polyethylenglykol 4000-und Natriumsulfit-Trenntechniken. Die intra- und interassay-Präzisionswerte liegen jedoch auch hierbei mit Ausnahme des Coated tube-Verfahrens unter $10 \%$ bzw. zwischen 10 und $20 \% \mathrm{VK}$.

Im Vergleich zu der für Poolserum von Blutspendern ermittelten interassay-Präzision von 15\% VK für die Digoxinund von $13 \%$ VK für die Insulin-Bestimmungen verschlechtern die drei untersuchten Störfaktoren Hämolyse, Harnstoff und Bilirubin die interassay-Präzision nur unwesentlich.

\section{Effects of haemolysis, urea and bilirubin on the precision of digoxin and insulin radioimmunoassays}

Summary: The influence of haemolysis, uraemia and hyperbilirubinaemia on the radioimmunoassay for both digoxin and insulin has been investigated for five separation techniques (dextran/charcoal; coated tube; polyethyleneglycol 4000; sodium sulphite; double antibody). Recoveries, and intra- and interassay precision were calculated. It was demonstrated that even in serum samples with a rather high degree of haemolysis (haemoglobin up to $50 \mathrm{~g} / \mathrm{l}$ ) digoxin can be measured by using each of the five separation techniques without any significant interference. Visible haemolysis (haemoglobin above $200 \mathrm{mg} / \mathrm{l}$ ) leads either to disturbance or to a complete failure of insulin radioimmunoassays with all separation techniques. This effect can be largely neutralized, and precision improved, by using $\mathrm{N}$-ethylmaleimide. With the exception of the coated tube separation technique the intraassay precision has a $\mathrm{CV}$ of $<10 \%$, and the interassay $\mathrm{CV}$ is between 10 and $20 \%$. Elevated urea concentrations interfered in the digoxin radioimmunoassay only when the coated tube technique was used. The insulin radioimmunoassay, however was affected by high urea when either the double antibody or the coated tube technique was used. Here the intraassay precision also has a coefficient of variation $<10 \%$, the interassay CV lying between 10 and $20 \%$. Bilirubin influenced the digoxin test when the sodium sulphite separation was used, and it affected the insulin determinations with polyethyleneglycol 4000 and sodium sulphite. The intra- and interassay precision were however also around $10 \%$ and between 10 and $20 \%$ respectively. Compared with the interassay precision of $15 \% \mathrm{CV}$ for digoxin and $13 \%$ for insulin for a poolserum from blood donors, the decrease of interassay precision caused by haemolysis, uraemia and hyperbilirubinaemia was insignificant. 


\section{Einführung}

Das gencrelle Ziel von Untersuchungen zur Qualitätskontrolle radioimmunologischer Verfahren ist es, eine Verbesserung von Prïzision und Richtigkeit dieser Verfahren zu erreichen und die Sicherheit der klinischen Diagnostik zu erhöhen. Diese Versuche werden in der Bundesrepublik Deutschland seit einigen Jahren vom Institut für Klinische Biochemie der Universität Bonn, vom Institut für Standardisierung und Dokumentation Düsseldorf sowie einer Endokrinologischen Arbeitsgruppe der Medizinischen Klinik Innenstadt der Universität München durchgeführt (1-15). Auf internationaler Ebene befaßt sich die WHO seit 1976 weltweit mit der Standardisierung und Qualitätskontrolle radioimmunologischer Hormonanalysen (16-18). Von den beiden erstgenannten Institutionen werden externe Qualitätskontrollversuche für einige Hormone in einem der Evaluation sonstiger klinisch-chemischer Kenngrößen analogen Vorgehen in freiwilliger Teilnahme durchgeführt. Da hierbei jedoch nur zwei Proben untersucht werden. sind Information und Analyse möglicher Fehlerquellen eingeschränkt. Die Münchner Arbeitsgruppe führt Versuche zur externen Qualitätskontrolle nach eigenem Modell durch, bei dem eine größere Probenzahl untersucht wird, wobei entsprechend Art und Menge der Proben weitergehendere Informationen zu
Besonderheiten von Testsystemen und deren Beeinflußbarkeit ermittelt und in Empfehlungen zu Testverbesserungen umgesetzt werden können. Auch für das Nichthormon Digoxin wurden Ringversuche nach beiden Modellen durchgeführt (19-22). Die WHO verwendet zur Qualitätskontrolle radioimmunologischer Hormonbestimmungen das aufwendigste Verfahren ("matched reagents programme"), bei dem'den Teilnehmern Reagenziensätze und Arbeitsanleitungen permanent zur Verfuggung gestellt werden. Es ist hierbei das Ziel, eine möglichst stabile und wenig ștöranfällige Methode für jedes Antigen herauszufinden, um sie dann als jeweilige Referenzmethode zu deklarieren $(17,18)$.

Aufgrund der Komplexität des radioimmunologischen Gesamtanalysènablaufs kann in Ringversuchen mit nur wenigen Proben anhand des Vergleichs der Ergebnisse mit dem wahrscheinlichsten Wert oder dem Referenzwert nur das Ausmaß der Abwëichung festgestellt werden, nicht aber ihre Ursache, da sie an unterschiedlichen Stellen in der Abfolge der Teilprozesse des Gesamtablaufs lokalisiert sein kann. Einige der Faktorèn, die durch ihren Einfluß auf Teilschritte oder Bestandteile einer radioimmunologischen Methode zu Ergebnisdifferenzen führen können, sind bekannt, weitere können lediglich vermutet werden oder sind unbekannt. Eine Aufstellung hierzu gibt Tabelle 1. Die Ergebnissè ver-

Tab. 1. Einflußgrößen, die bei radioimmunologischen Verfahren zu Resultatsunterschieden führeen können.

\begin{tabular}{|c|c|}
\hline $\begin{array}{l}\text { Bestandteil oder Teilschritt einer } \\
\text { radioimmunologischen Methode }\end{array}$ & Variable Faktoren, die zu Resultatsunterschieden führen können \\
\hline \multicolumn{2}{|l|}{ 1. Reagenzien } \\
\hline Standard-Antigen & Struktur, Reinheit, Stabilität, Proteinbindung \\
\hline Markiertes Antigen & $\begin{array}{l}\text { Art der Markierung, spezifische Radioaktivität, Stabilität, physikalisch-chemische Eigen- } \\
\text { schaften im Vergleich zum Standard-Antigen }\end{array}$ \\
\hline Antikörper & $\begin{array}{l}\text { Spezies, Art des Immunogens, Immunisierungsschema, Affinitätskonstante gegenüber mar- } \\
\text { kiertem und unmarkiertem Antigen }\end{array}$ \\
\hline Puffersystem & $\begin{array}{l}\text { Zusammensetzung, Ionenstärke, pH-Wert, Art und Konzentration des Schutzproteins, Zu- } \\
\text { sätze weiterer Reagenzien (z. B. Natriumazid, Enzyminhibitoren, Substanzen zur Verhinde- } \\
\text { rung ciner Protein-Antigen-Wechselwirkung) }\end{array}$ \\
\hline Standard-Matrix & Zusammensetzung \\
\hline 2. Probenmatrix & $\begin{array}{l}\text { Zusammensetzung (unphysiologische Konzentration physiologischer Bestandteile, unter- } \\
\text { schiedliche Konzentrationen unphysiologischer Bestandteile) }\end{array}$ \\
\hline 3. Probenvorbereitung & $\begin{array}{l}\text { Gewinnung, Lagerung, Versand, Vorbehandlung (Extraktion, Hitzebehandlung, Gerinnungs- } \\
\text { hemmung u. a.) }\end{array}$ \\
\hline 4. Dosierung und Verdünnung & Qualität von Dosierern bzw. mechanisierten Systemen, Materialiẹn \\
\hline 5. Reaktionsgefäßse & Material, Oberflächen/Volumen-Verhältnis \\
\hline 6. Inkubation & Temperatur, Zeit \\
\hline 7. Trenntechnik & $\begin{array}{l}\text { Art der b/f-Trennung, Einflüsse durch Komponenten der Probenmatrix, unspezifische Bin- } \\
\text { dungen }\end{array}$ \\
\hline 8. Radioaktivitätsmessung & Art und Qualität des Meßgerätes, statistischer Zählfehler \\
\hline 9. Auswertung & $\begin{array}{l}\text { Art und Qualität des Angleichverfahrens für die Standardkurve, individuelle unspezifische } \\
\text { Bindungen }\end{array}$ \\
\hline
\end{tabular}

J. Clin. Chem. Clin. Biochem. / Vol. 20, 1982 / No. 1 
schiedener Ringversuche $(11,14,19)$ zeigten, daß die Interlaboratoriums-Präzision für Proben auf Humanserum-Basis mit physiologischer Zusammensetzung der Komponenten auffällig besser ist als furr Proben, die physiologische Bestandteile in unphysiologischer Konzentration oder unphysiologische Bestandteile in unterschiedlicher Konzentration enthalten. Als Beispiel hierfür dient das Präzisionsprofil aus einem Digoxin-Ringversuch (19), in dem die Interlaboratoriums- bzw. interassay-Präzision für derartige Typen von Serumproben verglichen wird (Abb. 1).

Bei Interlaboratoriumsvergleichen durch Ringversuche können alle in Tabelle 1 genannten Faktoren durch ihren individuellen Einfluß auf unterschiedliche Testverfahren zur Verschlechterung der InterlaboratoriumsPräzision beitragen. Die Entwicklung auf dem Gebiet der Zuverlässigkeit radioimmunologischer Verfahren hat gezeigt, daß ein kontinuierlicher Mehraufwand an Untersuchungs-Material und -Methodik notwendig ist, um eine wirksame Verfahrens-Evaluation durchzufuhren, wobei auch ein derart umfangreiches Programm wie das der WHO nur eine begrenzte Anzahl von Probentypen und damit auch Störfaktoren untersuchen kann. Weitere Informationen zur Störanfälligkeit von Testverfahren kann man erhalten und eventuell auch bei der Ermittlung robuster Methoden berücksichtigen, wenn in systematischen Untersuchungen an exemplarischen radioimmunologischen Verfahren festgestellt wird, welche potentiellen Störfaktoren bei definierten Methoden zu groben

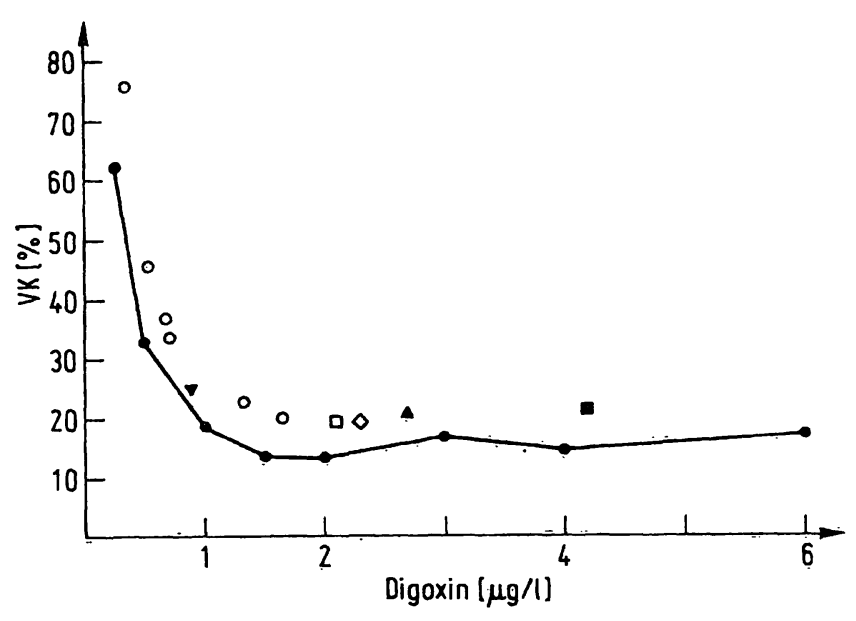

Abb. 1. Interlaboratoriums-Präzision der radioimmunologischen Digoxin-Bestimmung, crmittelt aus Daten eines Ringversuchs (19) mit 54 Methoden. Variationskoeffizienten (\%) in Abhängigkeit von der Digoxin-Konzentration in Serumproben mit physiologischer und unphysiologischer Zusammensetzung.

- Poolserumproben mit zugesetztem Digoxin

- Serumproben aus einer pharmakokinetischen Untersuchung

口 Hämolytische Serumprobe

- Serumprobe mit unphysiologischer Proteinzusammensetzung

- Serumprobe mit erhöhter Lipidkonzentration

$\checkmark$ Kontrollserum 1

- Kontrollserum 2
Abweichungen führen, die dann als Referenzmethoden zu wenig robust sind. Dieses ist anhand ausgewählter repräsentativer Methoden möglich, bei denen bis auf die zu untersuchenden Variablen weitere Parameter konstant gehalten werden können. Aus der Gruppe potentieller Teststörungen, die durch eine von humanem Spenderserum abweichende Probenmatrix-Zusammensetzung hervorgerufen werden können, werden die Einflüsse von Hämolyse, Harnstoff und Bilirubin auf jeweils funf radioimmunologische Methoden zur Bestimmung eines Steroidhaptens (Digoxin) und eines Peptidantigens (Insulin) untersucht.

\section{Material und Methoden}

Verwendete Reagenzien und Lösungen

E. Merck: 5,5-Dietylbarbitursäure Natriumsalz, zur Analyse: Natriumacetat, krist., zur Analyse; Natriumchlorid, krist., zur Analyse; Natriumazid; Natriumsulfit, wasserfrei, rein; Aktivkohle zur Analyse; Harnstoff zur Analyse; Bilirubin für biochemische Zwecke.

Sigma: N-Ethylmaleinimid.

Serva: Albumin aus Rinderserum lyophil. rein, $92 \% \mathrm{~min}$.; Immunglobulin aus Rinderserum lyophil. rein $98 \%$; Aktivkohle aus Holz Norit A.

Fluka AG: Dextran MG 80000 purum.

Merck-Schuchardt: Polyethylenglykol 4000 zur Synthese.

Hoffmann-La Roche: Liquemin 25000, Natrium-heparinat.

Hoechst AG: Insulin vom Schwein, ${ }^{125}$ I-markiert, spezifische Aktivität $6,475 \mathrm{GBq} / \mathrm{mg}(175 \mathrm{mCi} / \mathrm{mg})$, lyophil. getrocknct.

Boehringer/Mannheim: Antikörperbeschichtete Reaktionsgefäße aus der Testkombination zur radioimmunologischen Insulinbestimmung; antikörperbeschichtete Reaktionsgefäl $3 c$ aus der Testkombination zur radioimmunologischen Digoxin-Bestimmung: Digoxin- ${ }^{125}$ I-Derivat, spezifische Aktivität $18,5 \mathrm{GBq} / \mathrm{mg}$ ( $500 \mathrm{mCi} / \mathrm{mg}$ ); Digoxin, rcinst.

Calbiochem-Behring Corp.: Immunglobulin, guinea pig, shcep antibody to, lyophilized; Immunglobulin, rabbit, goat antibody to, lyophilized; serum, normal rabbit, lyophilized, B grade.

Novo: Insulin vom Schwein, $10 \times$ krist., $1 \mathrm{mg}=25 \mathrm{IE}$.

\section{Meerscliweinchenserum}

Mecrschweinchen wird in Ethernarkose Blut durch Herzpunktion entnommen und nach Gerinnung Serum gewonnen.

\section{Pufferlösung 1}

5,5-Diethylbarbitursäurc Natriumsalz $7,13 \mathrm{mmol} / \mathrm{l}$ : Natriumacetat $11,8 \mathrm{mmol} / 1$; Natriumchlorid $138 \mathrm{mmol} / \mathrm{l}$; Natriumazid 15,4 mmol/l; Albumin aus Rinderserum $5 \mathrm{~g} / 1 ; \mathrm{pH} 7,4$.

Pufferlösung 2

Pufferlösung $1 \mathrm{mit} 15 \mathrm{~g} / \mathrm{l}$ Immunglobulin aus Rinderserum.

Pufferlösung 3

Pufferlösung 1 ohne Albumin.

Insulin-Antikörper

Anti-Schwcineinsulin-Scrum vom Meerschweinchen.

\section{Digoxin-Antikörper}

Anti-Digoxin-Serum vom Kaninchen. Bei Antiserum-Verdünnungen von 1:250000 (Digoxin) und 1:250000 (Insulin) im Testansatz wird unter Verwendung von Polyethylenglykol 4000 als Trennmittel (175 g/l Endkonzentration) in 20 Stunden bei 
$4{ }^{\circ} \mathrm{C}$ und bei lïinsatz von $10000 \mathrm{Imp} / \mathrm{min}$ (Digoxin) bzw. $15000 \mathrm{Imp} / \mathrm{min}$ (Insulin) pro Testansatz jeweils die Hälfte des markierten Antigens spezifisch gebunden.

\section{Digoxin-Tracerlösungen}

${ }^{125}$ I-Digoxin-Derivat mit ciner spezifischen Radioaktivität von $18.5 \mathrm{~GB} q / \mathrm{mg}(500 \mathrm{mCi} / \mathrm{mg})$. Hieraus werden Lösungen mit $10000 \mathrm{lmp} / \mathrm{min} \cdot 100 \mu \mathrm{l}$ Pufferlösung 1 (Trenntechniken Polyethylengly'kol 4000: Dextran/Charcoal; Natriumsulfit; Coated tube) und mit $10000 \mathrm{lmp} / \mathrm{min} \cdot 100 \mu \mathrm{l}$ Pufferlösung 1 und $40 \mu \mathrm{l}$ Kaninchenserum pro $\mathrm{ml}$ Tracerlösung (Trenntechnik Doppelantikörper) hergestellt.

\section{Insulin-Tracerlösungen}

${ }^{125}$ I|Insulin vom Schwein mit einer spezifischen Radioaktivität von $6.475 \mathrm{GBq} / \mathrm{mg}(175 \mathrm{mCi} / \mathrm{mg})$. Hieraus werden Lösungen mit $15000 \mathrm{Imp} / \mathrm{min} \cdot 100 \mu \mathrm{l}$ Pufferlösung 1 (Trenntechniken Polyethylenglykol 4000; Dextran/Charcoal; Natriumsulfit), mit $15000 \mathrm{Imp} / \mathrm{min} \cdot 100 \mu \mathrm{l}$ Pufferlösung 1 und $40 \mu \mathrm{l}$ Meerschweinchenserum pro $\mathrm{ml}$ Tracerlösung (Trenntechnik Doppelantikörper) und mit $20000 \mathrm{Imp} / \mathrm{min} \cdot 1000 \mu \mathrm{l}$ Pufferlösung 1 (Trenntechnik Coated tube) hergestellt.

\section{Digoxin-Standards}

Durch Lösen von Digoxin in einer ethanolischen Lösung (12 $\mathrm{mmol} / 1$ Ethanol im Wasser) wird eine Lösung mit der Digoxin-Konzentration $1 \mathrm{~g} / 1$ hergestellt, mit Pufferlösung 1 auf $10 \mathrm{mg} / \mathrm{l}$ und mit Poolserum männlicher Blutspender auf 4, 2,1 und $0,5 \mu \mathrm{g} / \mathrm{l}$ verdünnt.

\section{Insulin-Standards}

$10 \times$ krist. Schweineinsulin wird in $0,03 \mathrm{~mol} / 1 \mathrm{HCl}$ gelöst, mit Pufferlösung 1 auf $100 \mathrm{E} / \mathrm{l}$ und mit insulinarmem Serum auf $160,80.40$ und $20 \mathrm{mE} / \mathrm{l}$ verdünnt.

\section{Probenvorbereitung}

Als Matrices zur Herstellung von Standards und Proben werden Poolserum männlicher Blutspender (Digoxin-Bestimmungen) und ein insulinarmes Poolserum (Insulin-Bestimmungen) verwendet. Die Entfernung von Insulin aus Poolserum erfolgt durch 18-stïndiges Rühren einer Suspension von $200 \mathrm{~g}$ Aktivkohle (Norit A) pro Liter Serum bei $4^{\circ} \mathrm{C}$, 8-stündige Zentrifugation bei $20000 \mathrm{~g}$ und $4^{\circ} \mathrm{C}$ und Filtration durch Glaswolle (23). Unter Bezug auf Insulin-Standards in Pufferlösung 2 und bei Anwendung der Polyethylenglykol 4000-Trenntechnik läßt sich in Wiederfindeversuchen durch Korrelation von zugesetztem und wiedergefundenem Insulin durch lineare Regression eine Erniedrigung der Insulinkonzentration in Poolserum mit diesem Verfahren von 21,3 auf $0,9 \mathrm{mE} / 1$ ermitteln.

\section{Hämolyse/N-Ethylmalcinimid}

Zur Herstellung eines Hämolysats wird heparinisiertes Spenderblut (Heparin-Natrium $75000 \mathrm{E} / 1$ Blut) $10 \mathrm{~min}$ bei $1000 \mathrm{~g}$ zentrifugiert, das Plasma verworfen, die zellulären Bestandteile zweimal mit physiologischer $\mathrm{NaCl}$-Lösung gewaschen, dreimal tiefgefroren und aufgetaut. Durch Zusatz des Hämolysats $(\mathrm{Hb} 350 \mathrm{~g} / \mathrm{l}$ ) zu Poolserum werden Proben mit HämoglobinKonzentrationen von $0,005-50 \mathrm{~g} / 1$ hergestellt. Die HämoglobinKonzentration wird mit Hilfe der Methämoglobincyanid-Methode mit einer modifizierten Drabkin-Lösung ermittelt $(24,25)$. Durch Lösen von N-Ethylmaleinimid in Poolserum wird eine Lösung mit einer Konzentration von $60 \mathrm{mmol} / \mathrm{l}$ hergestellt, aus der durch Zugabe von Hämolysat Proben mit Hb-Konzentrationen zwischen 0,005 und $27 \mathrm{~g} / 1$ resultieren.

\section{$\mathrm{N}-\mathrm{E}$ th ylmaleinimid}

Durch Lösen von N-Ethylmaleinimid in Poolserum und Verdünnen mit Poolserum werden Serumproben mit N-EthylmaleinimidKonzentrationen zwischen 12,5 und $100 \mathrm{mmol} / \mathrm{l}$ hergestellt.

Harnstoff

Wäßrige Harnstofflösung mit einer Konzentration von $10 \mathrm{~mol} / \mathrm{l}$ wird Spenderserum zugesetzt, so daß Serumproben mit zuge- setzten Harnstoff-Konzentrationen zwischen 10 und $80 \mathrm{mmol} / \mathrm{l}$ resultieren.

\section{Bilirubin}

$12 \mathrm{mg}$ Bilirubin werden mit $50 \mu \mathrm{l} 1 \mathrm{~mol} / 1 \mathrm{NaOH}$ intensiv gemischt und nach Zugabe von $950 \mu$ Poolserum bis zur vollständigen Lösung geschüttelt. Diese Lösung wird Poolserum zugesetzt, wobei Serumproben mit zugesetzten Bilirubin-Konzentrationen zwischen 30 und $977 \mu \mathrm{mol} / 1$ resultièren.

\section{Durchführung der Tests}

Zusammensetzungen und Testbedingungen für Digoxin- und Insulin- (in Klammern) Bestimmungen mit Trenntechniken Polyethylenglykol 4000, Dextran/Charcoal, Natriumsulfit und Doppelantikörper

Die Proben zur Bestimmung der Gesamt-Tracerbindung $\left(B_{0}\right)$, Tracerbindung in Gegenwart der Standards (BSt), unspezifischen Tracerbindung der Standarḍkurvenansätze (UBSt), Traçerbindung in Gegenwart der Probe (BPr), Tracerbindung in Gegenwart von Probe und Antigenzusatz $(B+\operatorname{Pr})$ und unspezifische Tracerbindung der Probenansätze (UBPr) werden jeweils in Triplikaten angesetzt. Volumeñangaben in $\mu \mathrm{l}$.

\begin{tabular}{|c|c|c|c|c|c|c|}
\hline & \multicolumn{3}{|c|}{ Standardkurve } & \multicolumn{3}{|c|}{ Proben } \\
\hline & $\mathrm{B}_{0}$ & $\mathrm{BSt}$ & UBSt & B⿳亠丷厂 & $\mathrm{B}+\mathrm{Pr}$ & UBPPí \\
\hline Standard/Probe & - & 50 & $=$ & 50 & 50 & 50 \\
\hline $\begin{array}{l}\text { Poolserum } \\
\text { (insulinarmes Serum) }\end{array}$ & $\begin{array}{c}50 \\
(50)\end{array}$ & - & $\begin{array}{c}50 \\
(50)\end{array}$ & - & - & - \\
\hline Tracerlösung & 100 & 100 & 100 & 100 & 100 & 100 \\
\hline Pufferlösung 1 & 50 & 50 & - & 50 & - & - \\
\hline $\begin{array}{l}1 \mu \mathrm{g} / 1 \text { Pufferlösung } 1 \\
(50 \mathrm{mE} / 1 \\
\text { Pufferlösung 1) }\end{array}$ & - & - & - & - & $\begin{array}{c}50 \\
(50)\end{array}$ & - \\
\hline $\begin{array}{l}10 \mathrm{mg} / 1 \text { Pेufferlösung } 1 \\
(100 \mathrm{E} / 1 \\
\text { Pufferlösung } 1)\end{array}$ & - & - & $\begin{array}{c}50 \\
(50)\end{array}$ & - & - & $\begin{array}{c}50 \\
(50)\end{array}$ \\
\hline Antikörperlösựng & 50 & 50 & 50 & 50 & 50 & 50 \\
\hline
\end{tabular}

Testzusammensetzungen für Digoxin- und Insulin- (in Klämmern) Bestimmungen mit der Coated tube-Technik

\begin{tabular}{|c|c|c|c|c|c|c|}
\hline & \multicolumn{3}{|c|}{ Ștandardkurve } & \multicolumn{3}{|l|}{ Proben } \\
\hline & $\mathrm{B}_{0}$ & BSt & UBSt & BPr & $\mathrm{B}+\mathrm{Pr}$ & UBPr \\
\hline $\begin{array}{l}\text { Standard/ } \\
\text { Probe }\end{array}$ & - & 100 & - & 100 & 100 & 100 \\
\hline $\begin{array}{l}\text { Poolserum } \\
\text { (insulinarmes } \\
\text { Serum) }\end{array}$ & $\begin{array}{c}100 \\
(100)\end{array}$ & - & 100 & - & - & $\ddot{-}$ \\
\hline Tracerlösung & $\begin{array}{c}500 \\
(1000)\end{array}$ & $\begin{array}{c}500 \\
(1000)\end{array}$ & $\begin{array}{c}500 \\
(1.000)\end{array}$ & $\begin{array}{c}500 \\
(1000)\end{array}$ & $\begin{array}{c}500 \\
(1000)\end{array}$ & $\begin{array}{r}500 \\
(1000)\end{array}$ \\
\hline $\begin{array}{l}\text { Puffer- } \\
\text { lösung } 1\end{array}$ & 100 & 100 & - & 100 & - & - \\
\hline $\begin{array}{l}1 \mu \mathrm{g} / 1 \text { Puf- } \\
\text { ferlösung } 1 \\
(50 \mathrm{mE} / 1 \text { Puf- } \\
\text { ferlösung } 1)\end{array}$ & - & - & - & - & $\begin{array}{c}100 \\
(100)\end{array}$ & - \\
\hline $\begin{array}{l}10 \mathrm{mg} / \mathrm{l} \text { Puf- } \\
\text { ferlösung } 1 \\
\text { (100 E/l Puf- } \\
\text { ferlösung } 1)\end{array}$ & - & - & $\begin{array}{l}100 \\
(100)\end{array}$ & - & - & $\begin{array}{r}100 \\
(100)\end{array}$ \\
\hline
\end{tabular}


Für dic Coated tube-Technik werden die Reaktionsansätze zur Digoxin-Bestimmung 2 Stunden bei Raumtemperatur, diejenigen zur Insulin-Bestimmung 16-20 Stunden bei Raumtemperatur inkubiert, der Inhalt wird abgesaugt und die Gefäße werden einmal mit Leitungswasser gespült.

Alle anderen Reaktionsansätze werden $16-20$ Stunden bei $4^{\circ} \mathrm{C}$ inkubiert. Nach halbstündigem Stehen bei Raumtemperatur erfolgt die Zugabe von $500 \mu 1$ Trennreagenz (Polyethylenglykol 4000, $263 \mathrm{~g} / 1$; Dextran/Charcoal in Pufferlösung 3, $1,25 / 12,5 \mathrm{~g} / 1$; zweiter Antikörper in optimaler Verdünnung in Pufferlösung 1), Mischen und Stehenlassen für $2 \mathrm{~min}$ (Dextran/Charcoal), 10 min (Polyethylenglykol 4000; Natriumsulfit) bzw. 2 Stunden (Doppelantikörper) bei Raumtemperatur. Es wird $10 \mathrm{~min}$ bei $2000 \mathrm{~g}$ zentrifugiert, $600 \mu \mathrm{l}$ Überstands-Aliquot mit einem automatischen Verdünnungsgerät abgenommen und die gebundene Radioaktivität oder die gebundene und die freie Radioaktivität bis zu einer Impulssumme von $10000 \mathrm{Imp} / \mathrm{min}$ gemessen.

\section{Berechnung}

Die Berechnung der Konzentrationen in den Proben erfolgt mit Hilfe der geglätteten Spline-Approximation $(26,27)$ an einem HP 9835 A-Rechnersystem, wobei eine individuelle Korrektur für die unspezifische Bindung erfolgt (28). Die Berechnung von spezifischer (B) und unspezifischer (UB) Bindung erfolgt für die unterschiedlichen Trenntechniken nach:

$\%$ B bzw. \%UB $=\left(1-\frac{\operatorname{Imp} / \min \ddot{U} \cdot F}{\operatorname{Imp} / \min \ddot{U}+\operatorname{Imp} / \operatorname{minS}}\right) \cdot 100$

für Trenntechniken Polyethylenglykol 4000, Natriumsulfit, Doppelantikörper

$\% B$ bzw. \%UB $=\left(\frac{\mathrm{Imp} / \min \ddot{U} \cdot \mathrm{F}}{\mathrm{Imp} / \min \ddot{U}+\operatorname{Imp} / \min S}\right) \cdot 100$

für Trenntechnik Dextran/Charcoal

\%B bzw. \%UB $=\left(\frac{\mathrm{Imp} / \mathrm{min} \text { gebunden }}{\mathrm{Imp} / \mathrm{min} \text { total }}\right) \cdot 100$

für Trenntechnik Coated tube

$F=\frac{\text { Gesamtrolumen }}{\text { abgenommenes Aliquot-Volumen }}$

Imp/minü $=$ Radioaktivität des Überstands-Aliquots Imp/minS = Radioaktivität des Sediments + Restüberstand

Der Faktor $\mathrm{F}$ wird entweder durch Wägung ermittelt oder abcr in Reaktionsansätzen, denen anstelle des jeweiligen Trennmittels ein identisches Volumen Wasser zugesetzt wird.

Aus den Konzentrationswerten für die Probe mit und ohne Antigen- bzw. Hapten-Zusatz wird die Wiederfindung berechnet.

Die intraassay-Präzision wird als Variationskoeffizient berechnet aus Mittelwert und Standardabiweichung aller Einzelwerte der mit einer Trenntechnik bei allen Proben des entsprechenden Typus von Störeinfluß ermittelten Konzentrationen.

Die interassay-Präzision wird als Variationskoeffizient berechnet aus Mittelwert und Standardabweichung aller Einzelwerte der mit 5 Trenntechniken bei einer Probe des entsprechenden Typus von Störeinfluß ermittelten Konzentrationen.

\section{Ergebnisse und Diskussion}

Bei radioimmunologischen Bestimmungen sind die ermittelten Konzentrationswerte die Resultante aus spezifischen und unspezifischen Bindungen bzw. Effekten. Weil darüberhinaus im Verhalten der unspezifischen Bindungen auch Einflüsse auf das Testsystem erkannt werden können, die außerhalb der eigentlichen AntigenAntikörper-Reaktion liegen, werden beide Kenngrößen in Abhängigkeit der jeweiligen Variablen separat dargestellt: die spezifische Bindung als \% Bindung oder \% Wiederfindung, die unspezifische Bindung als \% Bindung.

\section{Hämolyse/Digoxin}

Den Einfluß von Hämolyse auf die radioimmunologische Digoxin-Bestimmung gibt Abbildung 2 wieder. (Das Ausmaß an Hämolyse wird durch die Konzentration an freiem Hämoglobin angegeben; ab etwa $200 \mathrm{mg} / \mathrm{l}$ wird Hämolyse sichtbar). Mit Ausnahme der Doppelantikörper-Trenntechnik, bei der es erst bei extrem hohen $\mathrm{Hb}$ Konzentrationen zu einer falsch positiven Wiederfindung kommt, hat Hämolyse bis hin zu hohen Hämolysegraden weder Einfluß auf die Wiederfindung noch auf die unspezifische Bindung bei den vier weiteren Trenntechniken. Der Vergleich der intraassay-Präzision für $\mathrm{Hb}$ Konzentrationen von $0-200 \mathrm{mg} / \mathrm{l}$ und $200-10000 \mathrm{mg} / \mathrm{l}$ zeigt eine geringfügige Verschlechterung im Bereich der sichtbaren und starken Hämolyse an (Tab. 2), die interassay-Präzisionsdaten lassen keinen deutlichen Einfluß mit zunehmender Hämolyse erkennen (Tab. 3).

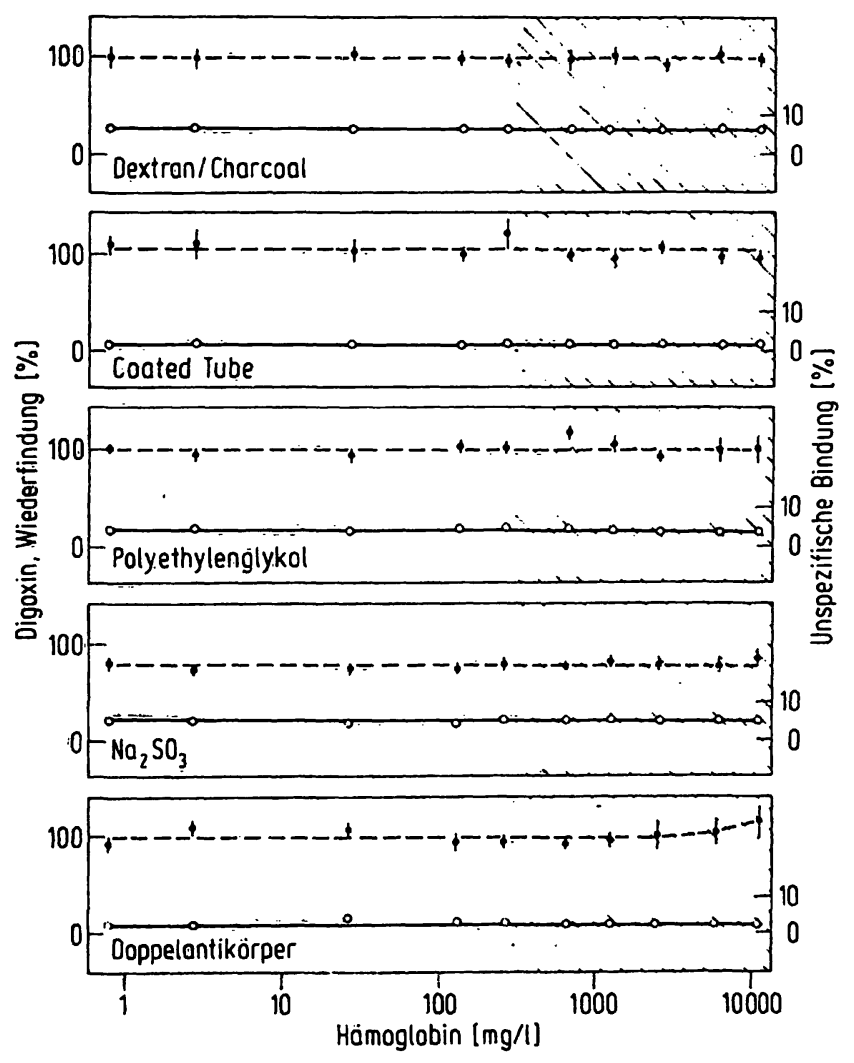

Abb. 2. Wiederfindung $(\bar{x} \pm s ; n=3)$ und unspezifische Bindung $(\bar{x}$ aus $n=3$ ) für fünf Trenntechniken bei der radioimmunologischen Digoxin-Bestimmung in Abhängigkeit von der Hämoglobin-Konzentration.

linke Ordinate: $\quad \%$ Wiederfindung $(\bullet)$

rechte Ordinate: $\quad \%$ unspezifische Bindung $(0)$

Abszisse:

Hämoglobin-Konzentration in $\mathrm{mg} / \mathrm{l}$ Testansatz

schraffierter Bereich: sichtbare bis starke Hämolyse 
Tab. 2. Intraassay-Präzision radioimmunologischer Digoxin- und Insulin-Bestimmungen in Abwesenheit und in Gegenwart von $\mathrm{N}$-Ethylmaleinimid ( $12 \mathrm{mmol} / \mathrm{l}$ Testansatz) bei geringer $(\mathrm{Hb} ; 0-200 \mathrm{mg} / \mathrm{l})$ und bei starker $(\mathrm{Hb} ; 200-$ $10000 \mathrm{mg} / \mathrm{l})$ Hämolyse. VK (\%) aus $\overline{\mathrm{x}} \pm \mathrm{s}$ bei $\mathrm{n}=15$.

\begin{tabular}{|c|c|c|c|c|c|c|}
\hline \multirow[t]{3}{*}{$\begin{array}{l}\text { Trenntecl- } \\
\text { niken }\end{array}$} & \multicolumn{2}{|c|}{ Digoxin } & \multicolumn{2}{|c|}{ Insulin } & \multicolumn{2}{|c|}{$\begin{array}{l}\text { Insulin/ } \\
\text { N-Ethyl- } \\
\text { malcinimid }\end{array}$} \\
\hline & \multicolumn{2}{|c|}{$\mathrm{Hb}(\mathrm{mg} / \mathrm{l})$} & \multicolumn{2}{|c|}{$\mathrm{Hb}(\mathrm{mg} / \mathrm{l})$} & \multicolumn{2}{|c|}{$\mathrm{Hb}(\mathrm{mg} / \mathrm{l})$} \\
\hline & $\begin{array}{l}0- \\
200\end{array}$ & $\begin{array}{l}200- \\
10000\end{array}$ & $\begin{array}{l}0- \\
200\end{array}$ & $\begin{array}{l}200- \\
10000\end{array}$ & $\begin{array}{l}0- \\
200\end{array}$ & $\begin{array}{l}200- \\
10000\end{array}$ \\
\hline $\begin{array}{l}\text { Dextran/ } \\
\text { Charcoal }\end{array}$ & 6.4 & 8,4 & 6,8 & $>43$ & 8,3 & 8,7 \\
\hline Coated tube & 12,2 & 8,4 & 14,2 & $>50$ & 18,4 & 13,9 \\
\hline $\begin{array}{l}\text { Polyethylen- } \\
\text { glykol } 4000\end{array}$ & 6,5 & 10,8 & 5,3 & $>30$ & 8,4 & 21,5 \\
\hline $\begin{array}{l}\text { Natrium- } \\
\text { sulfit }\end{array}$ & 7,7 & 7,9 & 5,8 & $>44$ & 8,9 & 14,4 \\
\hline $\begin{array}{l}\text { Doppel- } \\
\text { antikörper }\end{array}$ & 10,3 & 17,5 & 10,9 & $>28$ & 8,2 & 23,5 \\
\hline
\end{tabular}

Tab. 3. Interassay-Präzision radioimmunologischer Digoxin- und Insulin-Bestimmungen (Trenntechniken: Dextran/Charcoal; Coated tube; Polyethylenglykol 4000; Natriumsulfit; Doppelantikörper) in Abwesenheit und in Gegenwart von $\mathrm{N}$-Ethylmaleinimid (12 mmol/1 Testansatz) und in Abhängigkeit vom Hämolysegrad (Hb; $\mathrm{mg} / \mathrm{l}$ Testansatz) VK $(\%)$ aus $\bar{x} \pm s$ bei $n=15$.

\begin{tabular}{cccc}
\hline $\begin{array}{l}\text { Hämoglobin- } \\
\text { konzentration } \\
\text { (mg/l) }\end{array}$ & Digoxin & Insulin & $\begin{array}{l}\text { Insulin/ } \\
\text { N-Ethyl- } \\
\text { maleinimid }\end{array}$ \\
\hline 0,8 & 11,5 & 15,8 & 5,6 \\
2,6 & 16,5 & 15,2 & 7,6 \\
25 & 15,0 & 15,4 & 14,6 \\
128 & 10,7 & 15,1 & 18,1 \\
257 & 14,8 & 11,1 & 12,7 \\
630 & 16,2 & $>14,5$ & 13,8 \\
1230 & 13,0 & $>32,0$ & 18,4 \\
2450 & 11,9 & $>38,0$ & 18,0 \\
5960 & 16,6 & - & 24,8 \\
10600 & 20,7 & - & - \\
\hline
\end{tabular}

\section{Hämolyse/Insulin}

Der Einfluß zunehmender Hämolyse auf die Insulin-Bestimmung insbesondere im Gebiet der sichtbaren Hämolyse geht aus den drastischen Veränderungen der Wiederfinderaten (Abb. 3), der Verschlechterung der intraassay-Präzision (Tab. 2) sowịe der interassay-Präzision (Tab. 3) hervor. Auch die unspezifischen Bindungen zeigen einen Einfluß auf den Test an. Insbesondere der Anstieg der unspezifischen Bindung bei der Trenntechnik Dextran/Charcoal zeigt, daß innerhalb der 1620stündigen Inkubationszeit ein vom Hämolysegrad abhängiger Abbau zu Produkten provoziert wird, die in ihrem Adsorptionsverhalten gegenüber Dextran/Charcoal den durch Alterung ${ }^{125}$ Iod-markierten Insulins entste=

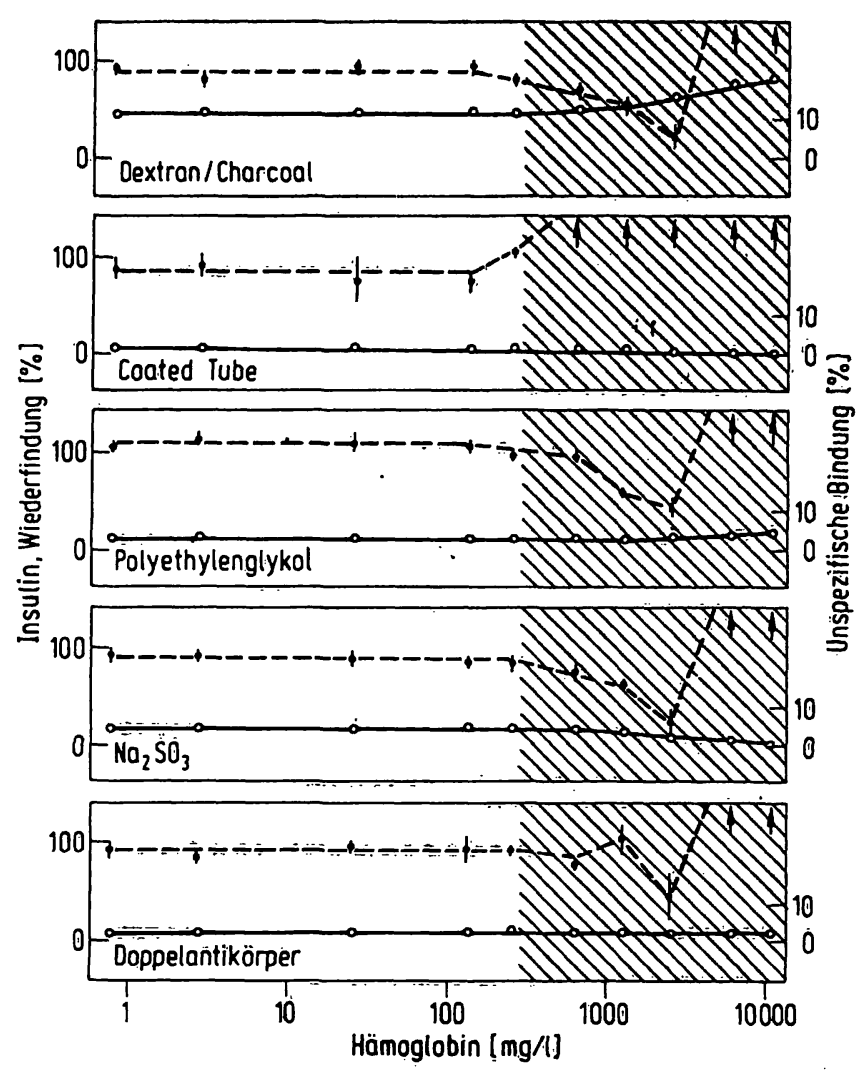

Abb. 3. Wiederfindung $(\bar{x} \pm s ; n \equiv 3)$ und unspezezifische Bindung ( $\bar{x}$ aus $n=3$ ) für fünf Trenntechniken bei der radioimmunologischen Insulin-Bestimmung in Abhängigkeit von der Hämoglobin-Konzentrạtion.

linke Ordinate: $\quad \%$ Wiederfindung $(\bullet)$

rechte Ordinate: $\quad \%$ unspezifische Bindung (o) Abszisse:

Hämoglobin-Konżentration in $\mathrm{mg} / \mathrm{l}$ Testansatz

schraffierter Bereich: sichtbare bis starke Hämolyse

henden Radiolyseproduktẹn ähneln (28). Der durch ein erythrocytäres Enzym verursachte Abbau, der sowohl unmarkiertes wie auch markiertes Insulin betrifft, kann durch N-Ethylmaleinimid gehemmt werden $(29,30)$. In Anwesenheit einer auch für den höchsten Hämolysegrad zur Enzymhemmung ausreichendem $\mathbb{N}$-EthylmaleinimidKonzentration von $12 \mathrm{mmol} / \mathrm{l}$ Testansatz wird im Bereich der sichtbaren und starken Hämolyse eine außerordentliche Verbesserung der intraassay-Präzision èrreicht (Abb. 4, Tab. 2), die interassay-Präzision ist im Vergleich zu derjenigen in Abwesenheit von N-Ethylmaleinimid bis zu höheren Hämolysegraden besser (Tab. 3). Um auszuschließen, daß N-Ethylmaleinimid in der angewandten Konzentration selbst einen Einfluß auf die Antigen-Antikörper-Bindung und/oder auf die unspezifische Bindung ausübt, werden beide Parameter in Abhängigkeit von der N-Ethylmaleinimid-Konzentration für die fünf Trenntechniken untersucht. Hierbei zeigt sich, daß erst $\mathrm{N}$-Ethylmaleinimid-Konzentrationen $>15 \mathrm{mmol} / \mathrm{l}$ bej drei Trenntechniken (Dextran/Charcoal; Pölyethylenglykol 4000; Doppelantikörper) zu einer geringfügigen Abnahme der spezifischen Bindung führen. 


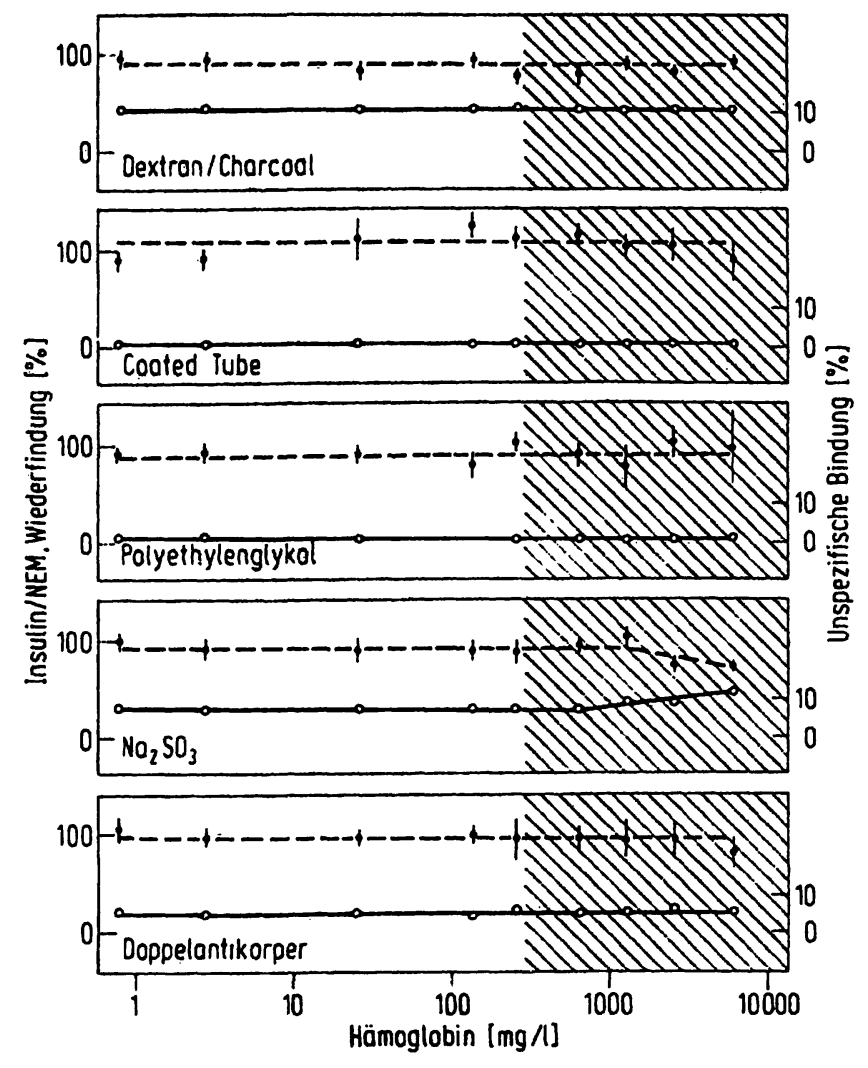

Abb. 4. Wiederfindung $(\bar{x} \pm s ; n=3)$ und unspezifische Bindung $(\bar{x}$ aus $n=3$ ) für fünf Trenntechniken bei der radioimmunologischen Insulin-Bestimmung in Gegenwart von $\mathrm{N}$-Ethylmaleinimid $12 \mathrm{mmol} / \mathrm{l}$ Testansatz in Abhängigkeit von der Hämoglobin-Konzentration.

linke Ordinate: $\quad \%$ Wiederfindung (๑)

rechte Ordinate: $\%$ unspezifische Bindung (o)

Abszisse: Hämoglobin-Konzentration in $\mathrm{mg} / 1$ Testansatz

schraffierter Bereich: sichtbare bis starke Hämolyse

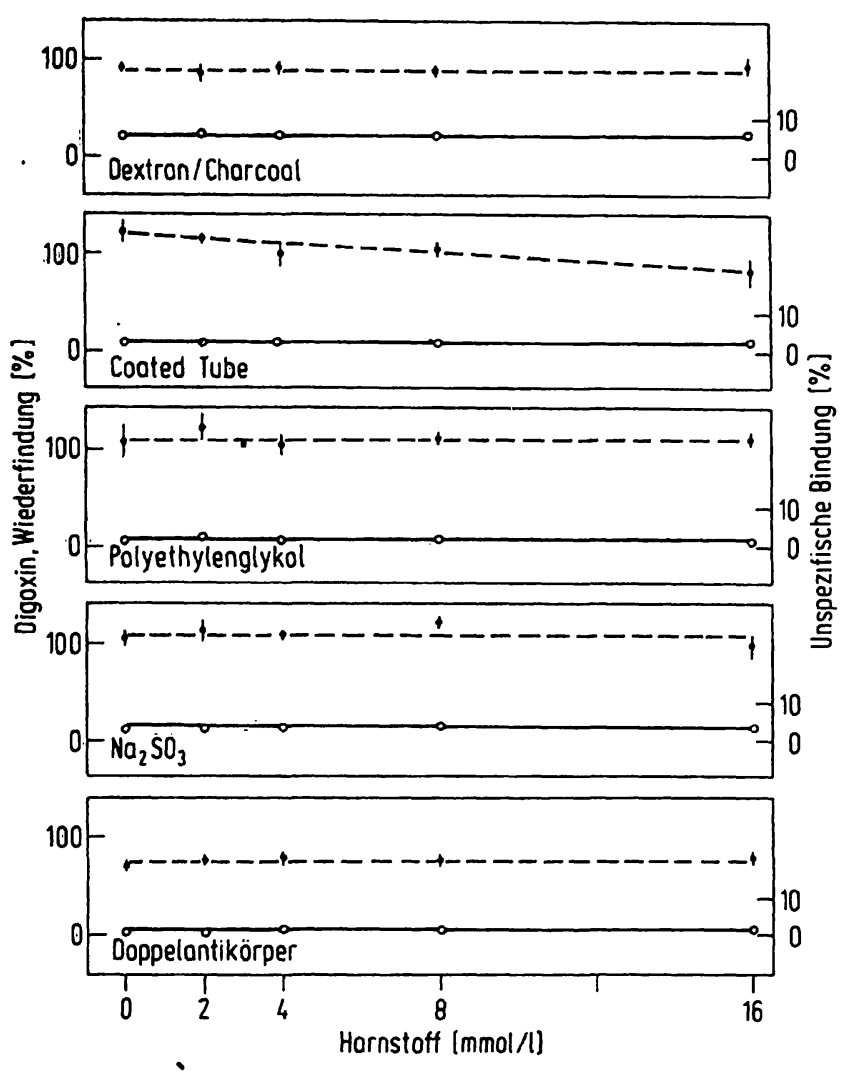

Abb. 5. Wicderfindung $(\bar{x} \pm s ; n=3)$ und unspezifische Bindung $(\bar{x}$ aus $n=3$ ) für fünf Trenntechniken bei der radioimmunologischen Digoxin-Bestimmung in Abhängigkeit von der Harnstoff-Konzentration.

linke Ordinate: $\quad \%$ Wiederfindung $(\bullet)$ rechte Ordinate: $\quad \%$ unspezifische Bindung (o) Abszisse:
Harnstoff-Konzentration in mmol/1 Testansatz zugesetzt

\section{Harnstoff/Digoxin}

Harnstoff-Konzentrationen bis zu $16 \mathrm{mmol} / \mathrm{l}$ Testansatz entsprechend $80 \mathrm{mmol} / 1$ Serum bzw. Plasma bewirken bei der Coated tube-Trenntechnik eine Abnahme der Wiederfindung, die weiteren Verfahren bleiben unbeeinflußt (Abb. 5). Analog den Ergebnissen aus den Un= tersuchungen zum Einfluß der Hämolyse liegt die in traassay-Präzision im Mittel unter $10 \%$ VK, die interạssạyPräzision zwischen 10 und 20\% VK. (Tab. 4 und 5).

\section{Harnstoff/Insulin}

Bei der Insulin-Bestimmung führen höhere HarnstoffKonzentrationen zu einem geringen Anstieg der Wiederfindung beim Coated tube-Verfahren, zu einem Abfall bei der Doppelantikörper-Trenntechnik (Abb. 6). Die intraassay-Präzisionsdaten für diese beiden Trenntechniken sind im Vergleich zu denen für die weiteren Trenntechniken schlechter (Tab. 4), die interassay-Präzision nimmt mit zunehmender Harnstoff-Konzentration ab (Tab. 5).

Tab. 4. Intraassay-Präzision radioimmunologischer Digoxin- und Insulin-Bestimmungen bei Zusatz von Harnstoff $(0-16 \mathrm{mmol} / \mathrm{l})$ bzw. Bilirubin $(0-195 \mu \mathrm{mol} / \mathrm{l})$ VK $(\%)$ aus $\bar{x} \pm s$ bei $n=15$

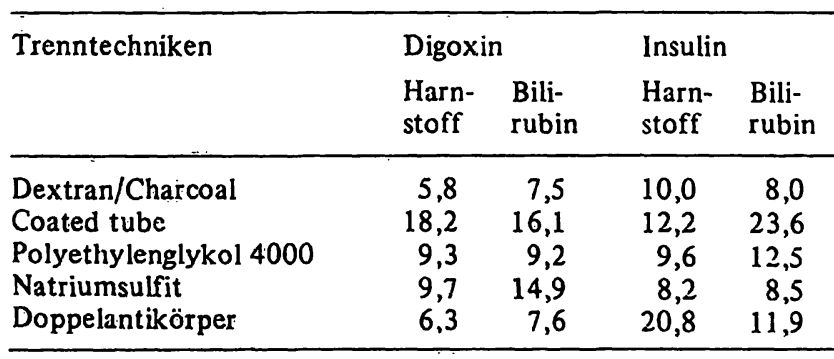

\section{Bilirubin/Digoxin}

Steigende Bilirubin-Konzentrationen führen bei der Natriumsulfit-Trenntechnik zu einem Ansticg der Wiederfindung (Abb. 7), der durch den parallelen Anstieg der unspezifischen Bindungen erklärt werden kann. Bei individueller Korrektur für die unspezifischen Bindun- 
Tab. 5. Interassay-Prizzision radioimmunologischer Digoxin- und Insulin-Best immungen (Trenntechniken: Dextran/Charcoal: Coated tube: Polyothylenglykol 4000: Natriumsulfit; Doppelantikörper) in Abhiingigkeit von der Harnstoff- bzw. Bilirubin-Konzentration. VK $(\%)$ aus $\bar{x} \pm s$ bei $n=15$.

\begin{tabular}{cccccc}
\hline $\begin{array}{l}\text { Harnstoff } \\
\text { zugesctzt } \\
\text { (mmol/l) }\end{array}$ & Digoxin & Insulin & $\begin{array}{c}\text { Bilirubin } \\
\text { zugesetzt } \\
(\mu \mathrm{mol} / \mathrm{l})\end{array}$ & Digoxin & Insulin \\
\hline 0 & 18,9 & 7,5 & 0 & 12,8 & 19,3 \\
2 & 20,6 & 10.0 & 6 & 19,2 & 18,4 \\
4 & 12,7 & 12,2 & 24 & 16,0 & 19,1 \\
$S$ & 16,7 & 12,8 & 49 & 16,6 & 20,4 \\
16 & 15,6 & 23,1 & 98 & 17,9 & 19,2 \\
& & & 195 & 22,9 & 20,3 \\
\hline
\end{tabular}

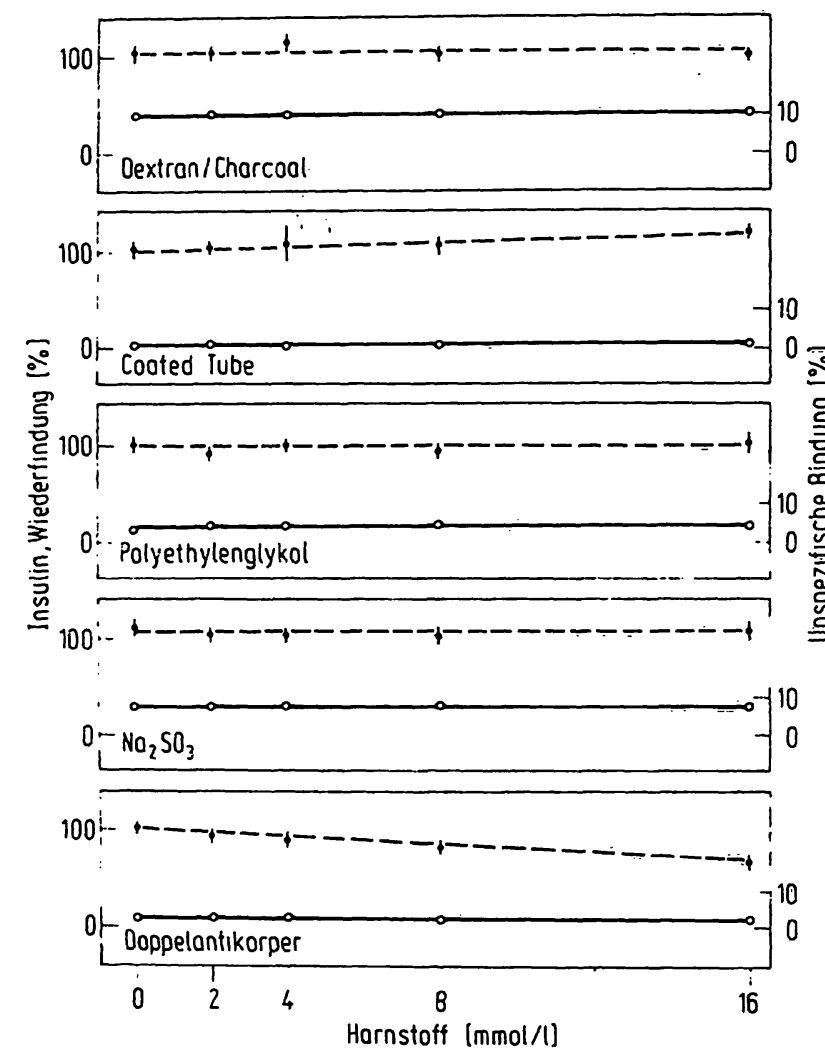

Abb. 6. Wiederfindung $(\bar{x} \pm s ; n=3)$ und unspezifische Bindung $(\bar{x}$ aus $n=3)$ für fünf Trenntechniken bei der radioimmunologischen Insulin-Bestimmung in Abhängigkeit von der Harnstoff-Konzentration.

linke Ordinate: $\quad \%$ Wiederfindung $(\bullet)$

rechte Ordinate: $\quad \%$ unspezifische Bindung (o) Abszisse:

Harnstoff-Konzentration in $\mathrm{mmol} / \mathrm{l}$ Testansatz zugesetzt

gen und bei der Berechnung der Wiederfindung aus der Differenz der ermittelten Konzentrationswerte mit und ohne Antigenzusatz steigen bei steigender unspezifischer Bindung die Konzentrationswerte mit Antigenzusatz stärker an als diejenigen ohne Antigenzusatz, so dał die hierdurch steigenden Differenzen zu erhöhten Wieder-

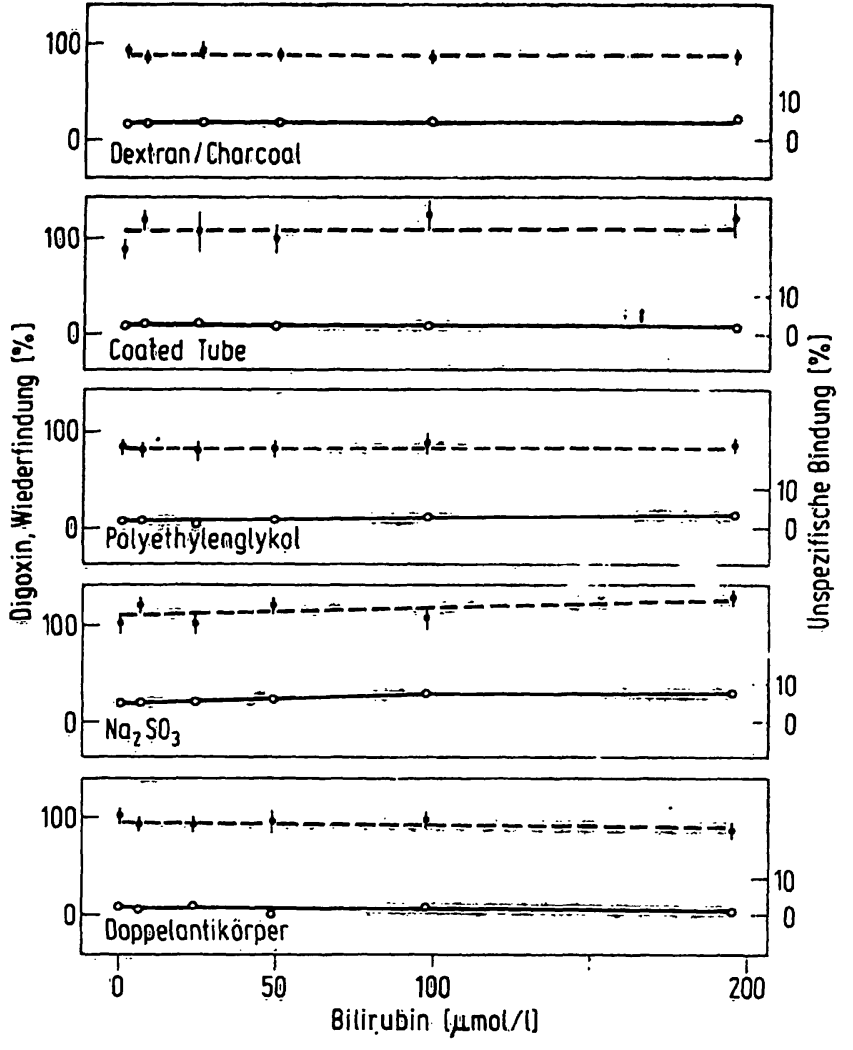

Abb. 7. Wiederfindung $(\bar{x} \pm s ; n=3)$ und unspezifische Bindung $(\bar{x}$ aus $n=3)$ füir fünif Trenntechniken bei der radioimmunologischen Digoxin-Bestimmung in Abhänğigkeèit von der Bilirubin-Konżentratioñ.

linke Ordinate: $\quad \%$ Wiederfindung $(\bullet)$

rechte Ordinate: $\quad \%$ unspezifische Bindung $(0)$

Abszisisse: $\mu \mathrm{mol} / 1$ Testansatż żugesetzt

finderaten führen. Diè intraassay- und interassay-Präzisionsdaten entšprechen denjenigen aụ den Untersuchun= gen zum Einfluß von Hämolyse bzw: Harñstoff (Tab. 4 und 5).

\section{Bilirubin/Insulin}

Bei der Insulin-Bestimmung mit Polyethylēnglykol 4000= Trenntechnik erhöht Bịlirubin geringüügig die Wiederfindung und erniedrigt sie im Falle der Natriumsulfit-Trenntechnik (Abb. 8). Die intraassay-Präzisionsdatèn für die Insulin-Bestimmung sind wie auch bei den Untersuchungen des Einflusses von Hämolyse und Harnstoff schlechter als diejenigen der Digoxin-Bestimmung, die interassayPräzision ist schlechter als die intraassay-Präzision und sie zeigt keine Abhängigkeit von der Bilirubin-Konzen: tration (Tab. 4 und 5).

\section{Schlußfolgerungen}

Bei der Berechnung von Wiederfindung und interassayPräzision über alle in dieser Untersuchung gemessenen Poolserumproben, denen keine störenden Komponenten zugesetzt worden sind, ergibt sich für Digoxin eine Wiederfindung von $97,2+14,6 \%(n=45)$ mit einem inter-

J. Clin. Chem. Glin. Biochem. / Vot'i20. 1982 / No.! 


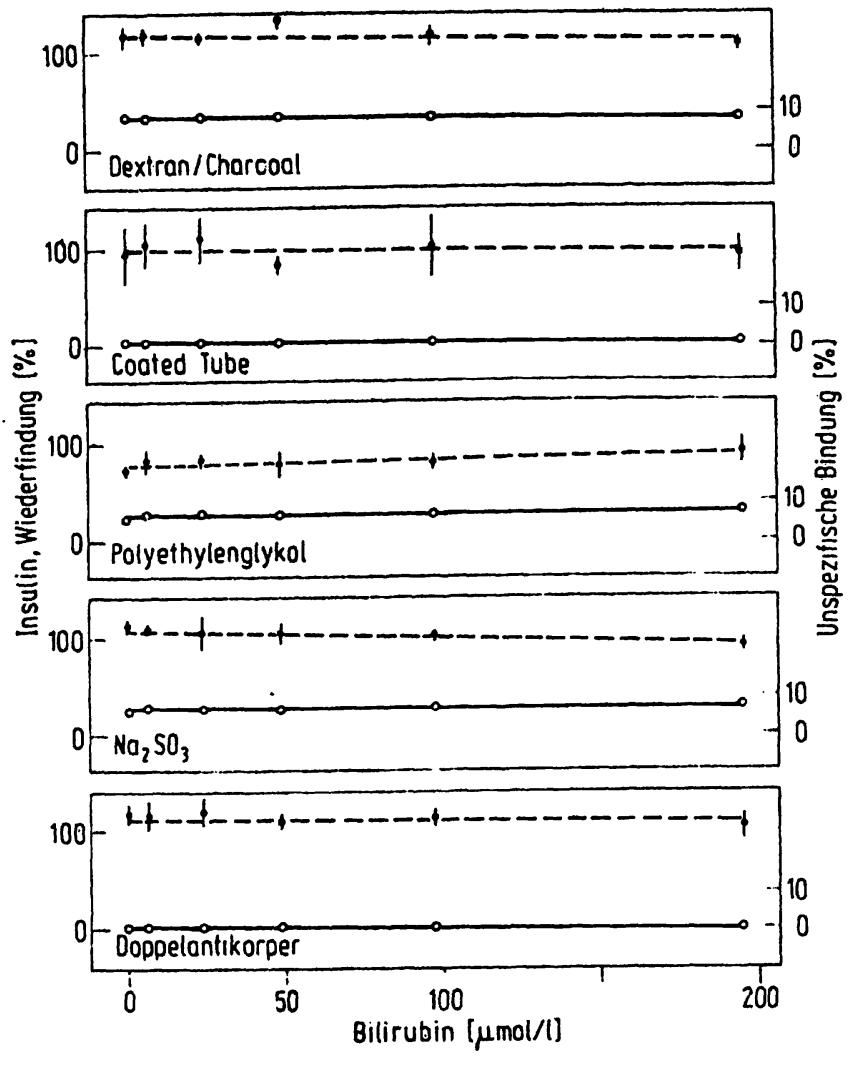

Abb. 8. Wiederfindung $(\bar{x} \pm s ; n=3)$ und unspezifische Bindung $(\bar{x}$ aus $n=3$ ) für fünf Trenntechniken bei der radioimmunologischen Insulin-Bestimmung in Abhängigkeit von der Bilirubin-Konzentration.

linke Ordinate: $\quad \%$ Wiederfindung $(\bullet)$ rechte Ordinate: $\%$ unspezifische Bindung ( $(0)$ Abszisse:
assay-Variationskoeffizienten von $15,1 \%$ sowie für Insulin eine Wiederfindung von $98,5+12,8(n=60) \mathrm{mit}$ einem interassay-Variationskoeffizienten von $13,0 \%$.

Diese Variationskoeffizienten setzen sich aus intra- und interindividueller Varianz des/der Untersucher (unterschiedliche Bearbeiter im cross-over-Verfahren), Präzision in der Serie und Präzision von Tag zu Tag sowie der interassay-Präzision zusammen und beinhalten somit alle auch bei Interlaboratoriums-Vergleichen bzw. Ringversuchen auftretenden Einflüsse mit Ausnahme der weitestmöglichen Konstanz und Vergleichbarkeit der Reagenzien und der Standardisierung der Durchführung. Der Vergleich mit der bei Hämolyse (bei der Insulin-Bestimmung in Gegenwart von N-Ethylmaleinimid), Urämie und Hyperbilirubinämie ermittelten interassay-Präzision mit Variationskoeffizienten zwischen 10 und $20 \%$ zeigt, daß diese Faktoren die interassay - (Interlaboratoriums-) Präzision nur unwesentlich beeinflussen und offensichtlich nicht zu der schlechteren Präzision beitragen, wie sie aus Interlaboratoriums- bzw. interassay-Untersuchungen bei radioimmunologischen Verfahren bekannt ist $(2,7,8,19-21)$. Die Ursachen hierfür liegen in der Vielfalt der Kombinationsmöglichkeiten der in Tabelle 1 genannten variablen Faktoren, deren gegenseitige Einflüsse zu untersuchen im einzelnen unmöglich ist. Insofern bieten das WHO-Programm oder analog konzipierte externe Qualitätskontroll-Untersuchungen wahrscheinlich den erfolgversprechendsten Weg, eine Verbesserung der $\mathrm{Zu}$ verlä̈ssigkeit radioimmunologischer Verfahren zu erreichen. Unterstützende Maßnahmen wie die systematische Untersuchung selektierter (potentieller) Störfaktoren sind hierbei geeignet, grobe Störeinflüsse zu erkennen und während der Entwicklung robuster Referenzmethoden rechtzeitig berücksichtigen zu können.

\section{Literatur}

1. Röhle, G., Breuer, H. \& Oberhoffer, G. (1975) Dtsch. Ärztebl. 72, 883-886.

2. Breuer, H., Jungblut, D., Marschner, I., Röhle, G., Scriba, P. C. \& Wood, W. G. (1978) in: Radioimmunoassay and Related Procedures in Medicine 1977, Vol II, International Atomic Energy Agency, Vienna, pp. 81-89.

3. Röhle, G. \& Breuer, H. (1978) Horm. Res. 9, 450-454.

4. v. Boroviczeny, K.-G., v. Klein-Wisenberg, A., Merten, R., Merten, U. P. \& Schumann, V. (1976) in: Exerpta Medica International Congress Series No. 384, Exerpta Medica, Amsterdam=Oxford, pp. 235-263.

5. Breuer, H. \& Siekmann, L. (1978̊) Endokrinologie-Informationen $2,8$.

6. Wood, W. G. (1977) J. Clin. Chem. Clin. Biochem. 15, $261-$ 266.

7. Marschner, I., Bottermann, P., Erhardt, F., Linke, R., Löffler, G., Maier, V., Schwandt, P., Vogt, W. \& Scriba, P. C. (1974) Horm. Metab. Res. 6, 293-296.

8. Marschner, I., Biro, G., Erhardt, F. W., Scriba, P. C. \& Weinges, K. (1975) Informationsblatt der Deutschen DiabetesGesellschaft Nr. 3, 1-9.

9. Erhardt, F., Marschner, I., Pickardt, R. C. \& Scriba, P. C. (1973) J. Clin. Chem. Clin. Biochem. 11, 381-387.
10. Marschner, I., Erhardt, F. W. \& Scriba, P. C. (1976) J. Clin. Chem. Clin. Biochem. 14, 345-351.

11. Horn, K., Marschner, I. \& Scriba, P. C. (1976) J. Clin. Chem. Clin. Biochem. 14, 353-360.

12. Wood, W. G., Marschner, I. \& Scriba, P. C. (1978) in: Radioimmunoassay and Related Procedures in Medicinc 1977, Vol III, International Atomic Energy Agency, Vienna, pp. 127-139.

13. Erhardt, F. W. \& Scriba, P. C. (1974) Ärztl. Lab. 20, 191 198.

14. Wood, W. G., Bauer, M., Marschner, I. \& Scriba, P. C. (1980) J. Clin. Chem. Clin. Biochem. 18, 183-192.

15. Wood, W. G., Bauer, M., Horn, K., Marschner, I., van Thiel, Dagmar, Wạchter, Christine \& Scriba, P. C. (1980) J. Clin. Chem. Clin. Biochem. 18,511-519.

16. Cresswell, M. A., Hall, P. E. \& Hurn, B. A. L. (1978) in: Radioimmunoassay and Related Procedures in Medicine 1977, Vol II, International Atomic Encrgy Agency, Vienna, pp. 149-157.

17. Hall, P. E. (1979) J. Stcroid Biochem. 11,113-116.

18. Hall, P. E. (1978) Horm. Res. 9, 440-449.

19. Dwenger, A., Friedel, R. \& Trautschold, I. (1978) in: Radioimmunoassay and Related Procedures in Medicine 1977, 
Vol II. International Atomic Energy Agency, Vienna, pp. $141-148$.

20. Fast. D. M., Hannon, W. H., Burtis, C. A. \& Bayse, D. D. (1980) Clin. Chem. 26, 480-486.

21. Hansell, J. R. (1979) Am. J. Clin. Pathol. 72, 341-345.

22. Bergdahl, B., Dahlström, G., Molin, L. \& Bertler, A. (1979) Acta Pharmacol. Toxicol. 45, 66-72.

23. Mitsuma, T., Colucci, J., Shenkman, L. \& Hollander, C. S. (1972) Biochem. Biophys. Res. Commun. 6. 2107-2113.

24. Zijlstra, W. G. \& Kampen, E. J. van (1960) Clin. Chim. Acta 5.719-726.

25. Zijlstra, W. G. \& Kampen, E. J. van (1962) Clin. Chim. Acta 7, 96-99.

26. Marschner, 1., Erhardt, F. \& Scriba, P. C. (1974) in: Radioimmunoassay and Related Procedures in Medicine, Vol I, International Atomic Energy Agency, Vienna, pp. 111122.
27. Marschner, I., Herndl, R. \& Scriba, P. C. (1980) J. Clin. Chem. Clin. Biochem. 18, 105-109.

28. Dwenger, A., Tost, P. \& Trautschold, I. (1977) J. Clin. Chem. Clin. Biochem. 15, 593-602.

29. Chandler, M. L. \& Varandani, P. T. (1972) Biochim. Biophys. Acta 286, 136-145.

30. Ukena, D., Dwenger, A. \& Trautschold, I. (1979) Berichtband der 14. Jahrestagung der Deutschen Diabetes-Gesellschaft, Freiburg 1979, C 25.

31. Hunter, W. M. \& McKenzie, I. (1979) Ann. Clin. Biochem. $16,131-146$.
Dr. rer. nat. Alex Divenger

Mediżinische Hochschule Hannover

Zentrum Biochemie

Abteilung Klinische Biochemie

Karl-Wiechert-Allee 9

D-3000 Hannover 61 